\title{
A CASE OF AUTOSOMAL DOMINANT BILATERAL FAMILIAL ANIRIDIA
}

Srinivas M. Ganagi ${ }^{1}$, Shivaraj Budihal ${ }^{2}$

\section{HOW TO CITE THIS ARTICLE:}

Srinivas M. Ganagi, Shivaraj Budihal. "A Case of Autosomal Dominant Bilateral Familial Aniridia". Journal of Evolution of Medical and Dental Sciences 2014; Vol. 3, Issue 16, April 21; Page: 4226-4230,

DOI: $10.14260 /$ jemds/2014/2422

ABSTRACT: Aniridia are rare developmental anomalies present in 1.8/100, 000 live births. Aniridia occurs due to abnormal neuroectodermal development secondary to mutations in paired box gene 6 (PAX6) on band p13 of chromosome 11 which regulates eye development. Aniridia may be congenital or traumatic. It may occur in isolation or be associated with a number of syndromes such as WAGR. Two third of cases are familial and one third is sporadic. We report a family of aniridia with different clinical spectrum of features.

KEYWORDS: Aniridia, PAX6, sporadic, nystagmus, cataract, glaucoma, keratopathy, fovea hypoplasia and optic disc hypoplasia.

CASE REPORT: A 9 month old female child was brought by mother to our hospital with complaints of involuntary movements of both eyes since birth. History of photophobia was present .No history of other systemic abnormalities. Birth history revealed she is second born child, FTND, 2nd degree consanguineous marriage. Family history revealed defective vision in mother since 20 years of age and similar history of defective vision in 4 year old sibling.

Examination of both eyes showed full extraocular movement with pendular nystagmus in all gazes. Anterior segment examination showed bilateral aniridia with clear lens (Figure 1). Fundus examination of both eyes showed clear media with normal disc and vessels with normal macula. Ultrasound abdomen was normal. Baby was referred to pediatrician who ruled out any systemic anomaly.

EXAMINATION OF SIBLING: Vision-RE-6/18 ph 6/12p, LE- 3/60 NIP, No nystagmus and full extraocular movement, Anterior segment examination showed B/L aniridia, B/L superiorly subluxated lens with posterior polar cataract (Figure 2 and3). Fundus examination of both eyes was normal. Tension RE $16 \mathrm{~mm}$ of hg, LE 18mm of hg.

EXAMINATION OF MOTHER: Vision-RE-1/60 NIP, LE-HM+. B/L moderate ptosis with fair LPS action, EOM showed pendular nystagmus in both eyes with divergent squint in left eye. Ocular examination revealed microcornea and corneal opacification with pannus formation, B/L aniridia with superiorly subluxated cataractous lens (Figure 4). Tension by Schiotz RE: 24mmHgLE: 22mmHg. Gonioscopy for visualization of angle structures and fundoscopy was not successful due to presence of corneal opacity. Regular follow up was advised for the child and cataract surgery for the sibling. Mother was started on antiglaucoma medications. 


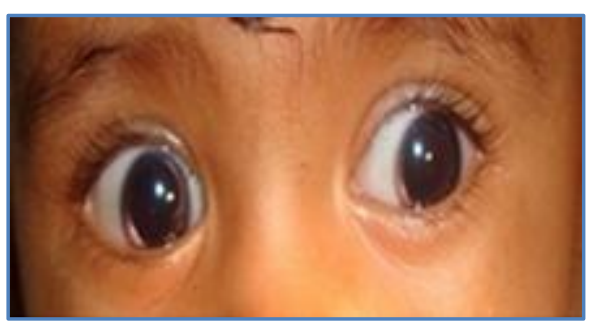

FIGURE: 1

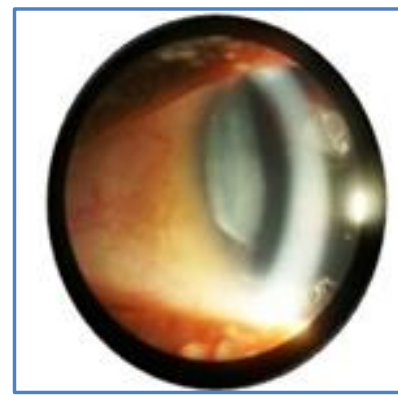

FIGURE: 3

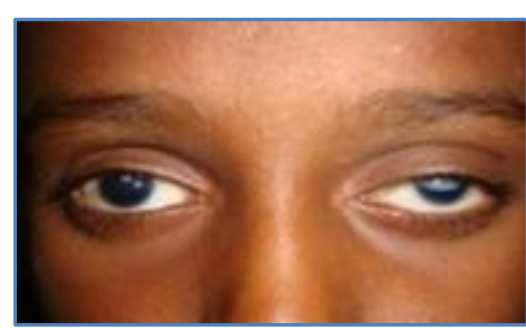

FIGURE: 2

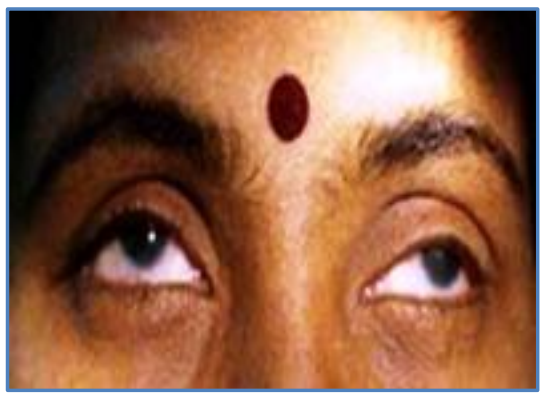

FIGURE: 4

DISCUSSION: Aniridia is a complex neuroectodermal developmental disorder characterized by variable degree of hypoplasia or the absence of iris tissue associated with multiple other ocular changes, some present from birth and some arising progressively over time. Aniridia has an estimated incidence of about 1.8/1,00, 000 live births. ${ }^{1}$ The term aniridia is a misnomer as iris tissue is usually present though its hypoplastic. Aniridia occurs secondary to mutations in PAX6 on band p13 of chromosome 11. Panocular changes occur as a result of mutation in PAX6 gene which is a developmental ocular gene.

These changes include alterations in corneal cytokeratin expression, cell adhesion and stemcell deficiency. ${ }^{2}$ It also has a fibrotic nature which may result in failure of many interventions such as penetrating keratoplasty and filtration surgery. However, there are few reported cases with no identified mutation of PAX6. ${ }^{3}$

3 phenotypes have been described. Autosomal dominant is most common seen in about $85 \%$ of cases and not associated with other systemic anomalies. Congenital sporadic seen in $13 \%$ of all aniridias and occurs in association with WAGR (Wilm's tumor, aniridia, Genitourinary anomalies \& Mental retardation) syndrome. Autosomal recessive seen in $2 \%$ of all aniridia cases associated with GILLESPIE'S SYNDROME (cerebellar ataxia and MR).Aniridia can be congenital or post traumatic. Post traumatic aniridia has been reported following contusive trauma associated with the rupture of the eye globe in which there was a total disinsertion of iris. ${ }^{4}$ Two thirds of all cases are familial, and one third is sporadic. ${ }^{5}$ It may occur in isolation or be associated with a number of syndromes such as WAGR (Wilm's tumor, bilateral sporadic aniridia, genitourinary abnormalities and mental retardation).

Aniridia is a pan ocular disorder affecting tissues throughout the eye, in addition to the iris abnormalities for which it is named. Most cases present within six weeks of birth with an obvious iris or papillary abnormalities or nystagmus. Affected individuals characteristically have absent or 
altered iris tissue and foveal hypoplasia, which generally leads to nystagmus and impaired visual

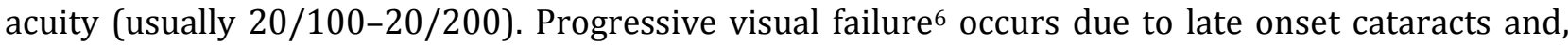
glaucoma and corneal opacification.

IRIS: Iris hypoplasia is the characteristic abnormality in aniridia presenting in severe cases as a small stump of residual iris tissue which can be visualized only on gonioscopy or ultrasound biomicroscopy to only transillumination defects with normal iris architecture in milder cases. ${ }^{7}$

CORNEA: Aniridia associated keratopathy is a relatively late and often progressive manifestation resulting from loss of cell adhesion and limbal stem cell failure ${ }^{8}$. Occurring in $20 \%$ of cases changes vary from mild peripheral vascularization to pancorneal vascularization, opacification and keratinization, cataract or glaucoma. Inadequate tear production is common, exacerbating the ocular surface problems.

GLAUCOMA: Glaucoma in aniridia usually occurs during the preadolescent or early adolescent years ${ }^{1}$ but may be present in infancy with large corneal diameter and corneal edema. It is thought to be due to developmental abnormalities in the drainage angle of the eye, which obstruct the outflow of aqueous humor. Grant and Walton ${ }^{9}$ have found that the stroma of the iris extends forwards onto the trabecular meshwork (TM) in the form of synechia-like attachments in the early stages, which later become a homogenous sheet, resulting in eventual angle closure.

CATARACT: Nelson et al found cataract in 50\%-85\% of patients with aniridia, being rare in infancy but visually significant lens opacities often develop in teen or early adulthood ${ }^{1}$. Occasionally there are remnants of the fetal vascularization of the anterior lens capsule (tunica vasculosa lentis) or a persistent papillary membrane.

POSTERIOR SEGMENT ABNORMALITIES: Optic nerve hypoplasia and foveal hypoplasia are common findings and these contribute to visual malfunction. Optic nerve hypoplasia is seen in $10 \%$ of cases and occasionally optic nerve colobomata are seen. ${ }^{10}$ Foveal hypoplasia is usually present and manifests as reduced foveal reflex, macular hypo pigmentation and crossing of the usual foveal avascular zone by retinal vessels. Aniridia may also be associated with retinal tears and detachments. ${ }^{11}$

ANIRIDIC FIBROSIS SYNDROME: Multiple intraocular surgeries sometimes trigger a fibrotic membrane to grow from the root of the iris tissue remnant behind the lens and cornea, causing displacement or entrapment of the intraocular lens (IOL) and corneal opacification. ${ }^{12}$

MANAGEMENT: Iris deficiency in aniridia is associated with visual disturbance with glare and photophobia which can be managed by measures such as eyelid surgery, corneal tattooing, and implantation of artificial irides. ${ }^{13}$ The use of a black diaphragm intraocular lens (IOL) to correct both congenital and traumatic aniridia has been advocated. ${ }^{14}$ These lenses include the Morcher aniridia IOL types $67 \mathrm{~F}$ and $67 \mathrm{G}$, the aniridia ring type 50C and the coloboma diaphragm type 96G. They can be placed in the ciliary sulcus or sutured trans-sclerally. 
Aniridia associated keratopathy can be managed in early stages using artificial tears for dry eye and dark glasses for photophobia. Autologous serum drops and amniotic membrane transplant facilitate survival and expansion of surviving limbal stem cells ${ }^{15}$ and can be tried in moderately severe cases. In severe cases limbal stem cell transplantation is needed. Penetrating keratoplasty has poor prognosis due to graft failure, however homologous lamellar limbo-keratoplasty appears to be quite effective in AAK. ${ }^{16}$

Managing glaucoma in aniridia is difficult with unsatisfactory results with medical management. Argon laser trabeculoplasty (ALT) ${ }^{17}$ and Diode laser photocoagulation both have been reported to have unsatisfactory results. Prophylactic goniotomy has been found to be quite effective in the prevention of glaucoma in patients with aniridia. ${ }^{18}$ The aim is to separate the abnormal extensions of iris stroma from the angle wall, thus preventing closure of the angle. Trabeculectomy has been found to be effective in the treatment of aniridic glaucoma. ${ }^{17}$

Guarded filtration surgery (GFS) using Ahmed, Molteno and Baervaldt implants has been found to be very effective in obtaining control in aniridic glaucoma with success rates ranging from $66 \%$ to $100 \%$. GFS may however be associated with complications such as prolonged hypotony, retinal detachment, migration of the tube, erosion of the tube through the conjunctiva and fibrosis of the anterior chamber. ${ }^{19}$ Cataract extraction is often necessary with or without IOL insertion. However, the anterior capsule of aniridia cataracts has been found to be very fragile ${ }^{20}$ hence, care must be taken during surgery to avoid capsular complications. The use of a black diaphragm IOL consisting of an opaque diaphragm surrounding the transparent optic has recorded satisfactory results. ${ }^{21}$

\section{REFERENCES:}

1. Nelson LB, Spaeth GL, Nowinski TS, Margo CE, Jackson L. Aniridia: A review. Surv Ophthalmol. 1984;28:621-642

2. Lee H, Khan R, O'Keefe M. Aniridia: current pathology and management. Acta Ophthalmol. 2008; 86(7); 708-715.

3. Traboulsi EI, Ellison J, Sears J, Maumenee IH, Avallone J, Mohney BG. Aniridia with preserved visual function: a report of four cases with no mutation ns in Pax6. Am J Ophthalmol. 2008; 145:760-764.

4. Talu S, Calugaru M. Posttraumatic aniridia - clinical reports. Oftalmologia.2003; 59(4):36-38.

5. Verloes A, Temple IK, Bonnet S, Bottani A. Coloboma, mental retardation, hypogonadism and obesity: critical review of the so-called Biemond syndrome type 2, updated nosology and delineation of three new syndromes. Am J Med Genet. 1997; 69:370-379.

6. Ramaesh T, Collinson JM, Ramaesh K, Kaufman MH, West JD, Dhillon B. Corneal abnormalities in Pax6 +/- small eye mice mimic human aniridia-related keratopathy. Invest Ophthalmol Vis Sci. 2003; 44:1871-1878.

7. Davis J, Duncan MK, Robison WG Jr, Piatigorsky J. Requirement for Pax6 in corneal morphogenesis: a role in adhesion. J Cell Sci. 2003; 116:2157-2167.

8. Tseng SC, Li DQ. Comparison of protein kinase C subtype expression between normal and aniridic human ocular surfaces: implications for limbal stem cell dysfunction in aniridia. Cornea. 1996; 15:168-178.

9. Grant WM, Walton DS. Progressive changes in the angle in congenital aniridia, with development of glaucoma. Trans Am Ophthalmol Soc.1974; 72:207-228. 
10. McCulley TJ, Mayer K, Dahr SS, Simpson J, Holland EJ. Aniridia and optic nerve hypoplasia. Eye (Lond) 2005; 19: 762-764.

11. Dowler JG, Lyons CJ, Cooling RJ. Retinal detachment and giant retinal tears in aniridia. Eye (Lond). 1995; 9:268-270.

12. Tsai JH, Freeman JM, Chan CC et al. A progressive anterior fibrosis syndrome in patients with postsurgical congenital aniridia. Am J Ophthalmol 2005; 140:1075-1079.

13. Burris TE, Holmes-Higgin DK, Silvestrini TA. Lamellar intrastromal corneal tattoo for treating iris defects (artificial iris). Cornea. 1998;17:169-173.

14. Sundmacher T, Reinhard T, Althaus C. Black diaphragm intraocular lens in congenital aniridia. Ger J Ophthalmol. 1994;3:197-201.

15. Lopez-Garcia JS, Garcia-Lozano I, Rivas L, Martinez-Garchitorena J. Congenital aniridia keratopathy treatment. Arch Soc Esp Oftalmol. 2006;81:435-444.

16. Holland EJ, Djalilian AR, Schwartz GS. Management of aniridic keratopathy with keratolimbal allograft: a limbal stem cell transplantation technique. Ophthalmology. 2003;110:125-130.

17. Wiggins RE, Tomey KF. The results of glaucoma surgery in aniridia. Arch Ophthalmol. 1992;110:503-505.

18. Chen TC, Walton DS. Goniosurgery for prevention of aniridic glaucoma. Trans Am Ophthalmol Soc. 1998;96:155-165.

19. Munoz M, Tomey KF, Traverso C, Day SH, Senft SH. Clinical experience with the Molteno implant in advanced infantile glaucoma. J Pediatr Ophthalmol Strabismus. 1991;28:68-72.

20. Schneider S, Osher RH, Burk SE, Lutz TB, Montione R. Thinning of the anterior capsule associated with congenital anirid2003;29:523-525.ia. J Cataract Refract Surg.

21. Beltrame G, Salvetat ML, Chizzolini M, et al. Implantation of a black diaphragm intraocular lens in ten cases of post-traumatic aniridia. Eur J Ophthalmol.2003;13(1):62-68.

\section{AUTHORS:}

1. Srinivas M. Ganagi

2. Shivaraj Budihal

\section{PARTICULARS OF CONTRIBUTORS:}

1. Associate Professor, Department of Ophthalmology, Srinivas Institute of Medical Science and Research Centre.

2. Assistant Professor, Department of Ophthalmology, Srinivas Institute of Medical Science and Research Centre.

\section{NAME ADDRESS EMAIL ID OF THE CORRESPONDING AUTHOR:}

Dr. Srinivas M. Ganagi, 303, Staff Quarters,

Srinivas Institute of Medical Science and Research Centre, Mukka, Surathkal,

Mangalore - 574146.

E-mail: srinivasganiga123@gmail.com

Date of Submission: 24/02/2014.

Date of Peer Review: 25/02/2014.

Date of Acceptance: 07/03/2014.

Date of Publishing: 16/04/2014. 